\title{
Woman of the House: Gender, Architecture, and Ideology in Dorset Prehistory
}

\author{
Genevieve LeMoine
}

\begin{abstract}
The role of women in Paleoeskimo households has rarely been examined. Careful application of analogies to Inuit culture reveal that there are both similarities and differences in how Late Dorset and Inuit gender roles are expressed in household organization. On an ideological level, Late Dorset women probably had a similar role to that of women in Inuit society, as the soul of the house and an important intermediary between hunters and the souls of the animals they hunted. On a day-to-day basis, however, Late Dorset women seem to have shared more of their labor as members of dual family households than did Inuit women, as members of nuclear family units. The increased importance of small, trapped game such as foxes and rabbits during Late Dorset times (Darwent 2001) may have contributed to the need for shared labor. Finally, women, in their role as keepers of the hearth, were important in maintaining community ties at seasonal aggregation sites dominated by long houses and external hearth rows.
\end{abstract}

\begin{abstract}
Dans presque tous les systèmes culturels, la charge symbolique de l'habitation est très forte. Celle de l'espace domestique paléoesquimau devait l'être tout particulièrement. En effet, l'organisation de celui-ci à partir de l'axe de symétrie constituée par la structure axiale se maintient rigoureusement pendant au moins 45 siècles, d'une extrémité à l'autre de l'écouméne paléoesquimau. [In virtually all cultures, habitation structures carry a very heavy symbolic load. This is especially true for Paleoeskimo dwellings. Their organization around the axis of symmetry defined by the axial feature is rigorously maintained for at least 45 centuries from one end of the Paleoeskimo world to the other.] (Plumet 1998, translation by the author)
\end{abstract}

\section{Introduction}

Some 1,500 years ago, the people of the eastern Canadian Arctic dramatically transformed their culture. This period, identified by archaeologists as a transition from Early/Middle Dorset to Late Dorset, is marked by a number of significant changes. Among these are: the re-occupation of the High Arctic islands after an abandonment of some 600 years; an increase in stylistic unifor- mity, evident primarily in organic tools, especially carvings (Lyons 1982); decreased residential mobility, indicated by bigger, less ephemeral houses and more intensively occupied sites; an increase in diet breadth and evenness (Darwent 2001); the appearance of large seasonal aggregation sites including long houses and external hearth rows; and increased long distance trade in exotic materials such as meteoric iron and native copper. The

Genevieve LeMoine, The Peary-MacMillan Arctic Museum

Bowdoin College, 9500 College Station, Brunswick, Maine 04011-8495 
Late Dorset population must have grown substantially from Middle Dorset levels to account for the reoccupation of the High Arctic. Perhaps related to this change, people engaged in widespread interactions, but were much more restricted in the areas they used on an annual basis than they had been just a few generations earlier. Extensive hunting areas were replaced by even more extensive relationships, embodied in trade goods and a common expression of ideology. Researchers know little, however, about how these changes came about, or what impact they had on the daily lives of the people who lived through them.
There has been a great deal of progress made in the last decade towards a richer view of prehistory, one in which gendered individuals act and interact to achieve their own ends, whether these be as simple as the manufacture of a particular tool, or as complex as the extension of ritual power over a rival captured in battle. Interest in these issues is not new; prehistorians have long striven to reconstruct the details of past lives, but new approaches to the past, from ethnoarchaeology to feminist theory, have provided us with valuable tools to approach questions of gender in a sophisticated and informed way. To date, application of these new approaches have been most fre-

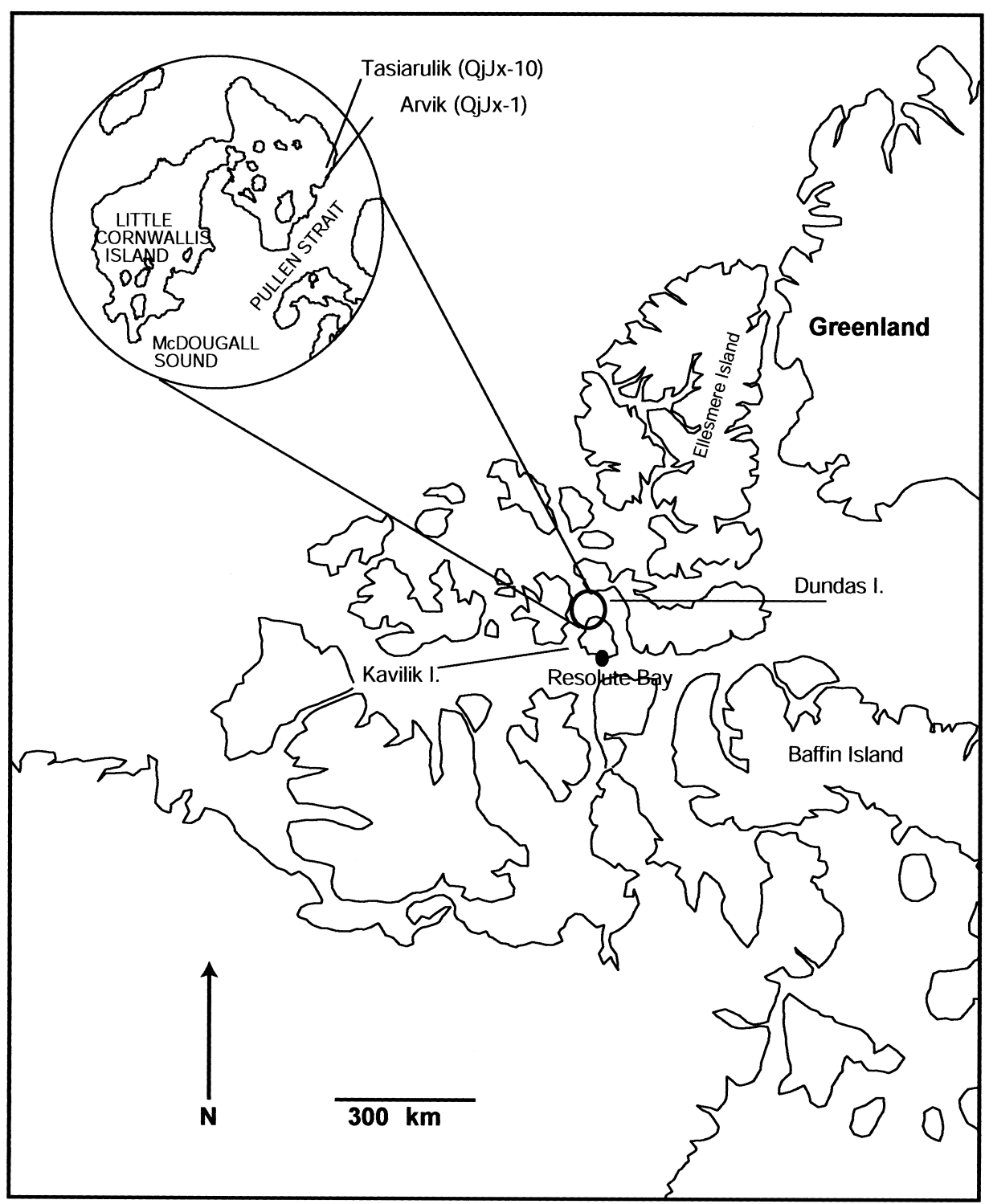

Figure 1. Map of the Central Arctic showing the location of the sites (inset). 
quent, and most successful, when there is a direct link to the written record-as always, historic and ethnographic documents greatly increase researchers' abilities to read the archaeological record. There are exceptions of course, but there is no getting around the fact that textual records (including written versions of oral histories and folklore) dramatically enhance our ability to "read" gender from sometimes-sparse archaeological remains. Archaeologists working with cultures that did not leave such records have a more difficult time investigating questions pertinent to contemporary theoretical developments. As has recently been pointed out (Conkey 2001; Gero 2001), the task is not easy, but neither is it impossible, if approached with the appropriate theoretical and analytical tools.

ㄴ. This paper makes a start in applying some of $\exists$ these approaches to the Late Dorset period of the eastern Arctic. This discussion focuses on the inöter-related issues of gender, household form, architecture, and ideology in Dorset society. These are ธิ่ of particular interest for a variety of reasons. The -concrete nature of much architecture gives it a $\rightarrow$ privileged place in archeology, enhanced by its intimate if not direct relationship to the household. ‡Houses are built to fulfill the needs of the occu$\overrightarrow{\mathrm{s}}$ pants, but they recursively influence occupant beE⿱ havior as well (Hillier and Hanson 1984) — they are sshaped by, and shape the physical, social, and ideE ological needs of their builders. Gender is of interest for its relevance to a whole variety of other ఫ्ञ social relationships, including production, reproduction, and redistribution (Moore 1994) both within and beyond the household. The link between them is strong and significant, laden with ideological significance. Households, comprised of the co-residents of a house, are, as Tringham (1991:101 ) states "the vehicle with which we may possibly make the invisible women of prehistory and their production visible."

\section{The Late Dorset on Little Cornwallis Island}

The archaeological material that forms the basis of this study comes from two Late Dorset sites located on the southeast coast of Little Cornwallis Island, in the central High Arctic (Fig. 1). These sites were the focus of research by University of Calgary researchers between 1989 and 1994 (Helmer 1989, 1991; Helmer et al. 1993, 1995a, 1995b).

Little Cornwallis Island is located in McDougall Sound, between Cornwallis and Bathurst Islands. It is a low-lying landmass composed primarily of limestone and dolomite (Dunbar 1956). The environment is primarily polar desert, with isolated instances of semi-desert and diverse terrain where vegetation is present (Babb 1974). All the sites discussed here are on the southeast coast of the island, facing Pullen Strait. The sites are on raised beaches, in a landscape dotted by small melt-water ponds. The island fauna today is restricted to small mammals (fox, hare) and occasional large herbivores-a small number of Peary caribou are rumored to live on the island, but in five years of field work we saw no evidence of them. We did see a lone muskox. Sea mammals are plentiful in the waters surrounding the island, as are migratory birds in the summer.

The two sites that were the primary focus of our research, Arvik (QjJx-1, see Fig. 2) and Tasiarulik (QjJx-10, see Fig. 3), are very large with many habitations and other features. Each was occupied in cold and warm seasons, as indicated by the presence of both semi-subterranean houses and tent rings. Both are long (over 700 meters) linear sites about one kilometer apart on fossil beaches, some four to five meters above modern sea level. A third site, QiLa-3, is located about eight kilometers away from the main sites and consists of a single semi-subterranean house with two associated middens. During three years of

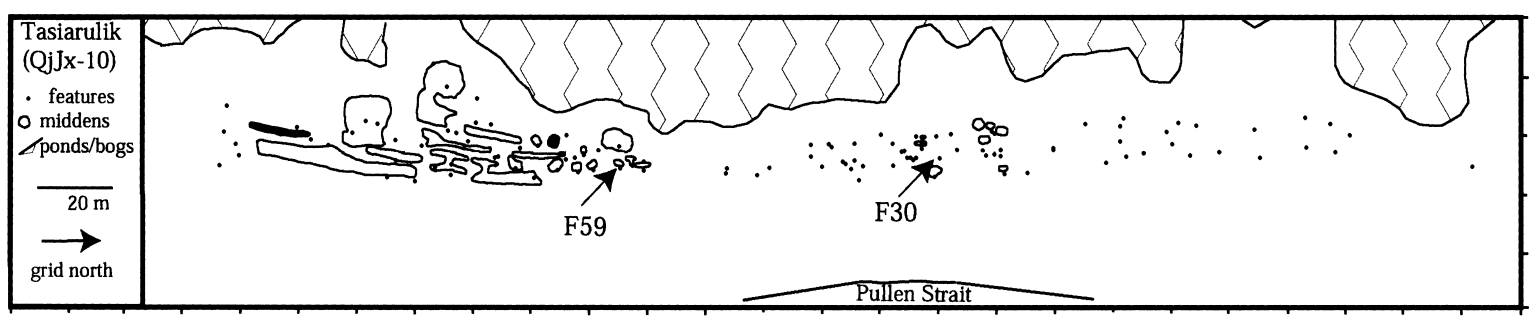

Figure 2. Plan of Tasiarulik, showing the location of the features discussed in the text. 
fieldwork, the University of Calgary team excavated 11 architectural features (as well as a number of middens, some directly associated with the dwellings) at these three Late Dorset sites (Helmer et al. 1993, 1995a, 1995b). At each of the two larger sites, at least two cold season and two warm season features were excavated. Associated middens were also sampled. At the third site the house was fully excavated and both middens sampled. This paper discusses four of these features, two cold season dwellings and two tent rings, selected for their preservation of architectural detail. A more detailed description of the architecture at these sites is available elsewhere (LeMoine et al., in press).

\section{Temigt Rings}

LatêDDorset tent rings, similar to those in other places, consist of a ring of rocks delimiting a roughtly oval feature. The rocks are presumed to have held down the hide covering of a tent. The ten ssupports were probably of driftwood, althouggh in no case have these survived. Ethnographically, tents were used in the brief summer whe snow, sod, or stone houses are uncomfortablezat best and most likely uninhabitable. Earlier Paleoskimo groups might have used skin structure during all seasons, perhaps insulating them witlow snow when posible. This is suggested based on absence of evidence for any better-insulated strutures. Late Dorset people, like Inuit, probably use tents only in the warm season. Tent size is differ to estimate accurately because the act of taking down the tent will displace the rocks, as

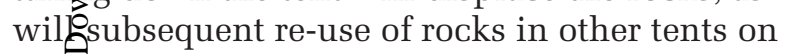
the same location or near by. Nevertheless, Dorset people appear to have used a wide range of tent sizes, as the rings vary considerably in size, from small ( 2 to $3 \mathrm{~m}$ maximum dimension) to large (5 $\mathrm{m})$. Axial features are found in some tent rings, as are a variety of hearth types (Maxwell 1985).

Tent features on Little Cornwallis Island exhibit variable preservation, ranging from a confused palimpsest of tent rings and middens in the central part of Tasiarulik to virtually undisturbed rings with intact interior features at both large sites. Well-preserved features at the sites exhibit some, but not all, of the variety described by Maxwell (1985). The rings at both Tasiarulik and Arvik tend to be larger than those reported elsewhere, ranging from $4 \times 3 \mathrm{~m}$ to $5 \times 5 \mathrm{~m}$. None have axial features, but the best-preserved have stone hearths. The first of these to be considered here, Feature 30 at Tasiarulik, is a large, diffuse, oval-to-circular ring of small boulders with interior measurements of $4.5 \times 5 \mathrm{~m}$ (Fig. $4 \mathrm{a}-\mathrm{b}$ ). As with the majority of the dwellings on Little Cornwallis Island, the long axis is perpendicular to the shoreline. There were two stone features inside the tent. One, in the northeast quadrant, was identified in the field as a cache. A second, in the center, was identified as a hearth. It was composed of fire-reddened slabs and boulders, although no charcoal was recovered. The artifact assemblage from this feature included a dense concentration of small chert flakes, ivory flakes, and antler shavings as well as a variety of typical Late Dorset objects. The faunal assemblage was dominated by the bones of migratory waterfowl, available only in the summer in this area.

Feature 53 at Arvik was similarly well-preserved (Figure 5a-b). The exterior ring is not as evident here (some rocks may have been re-

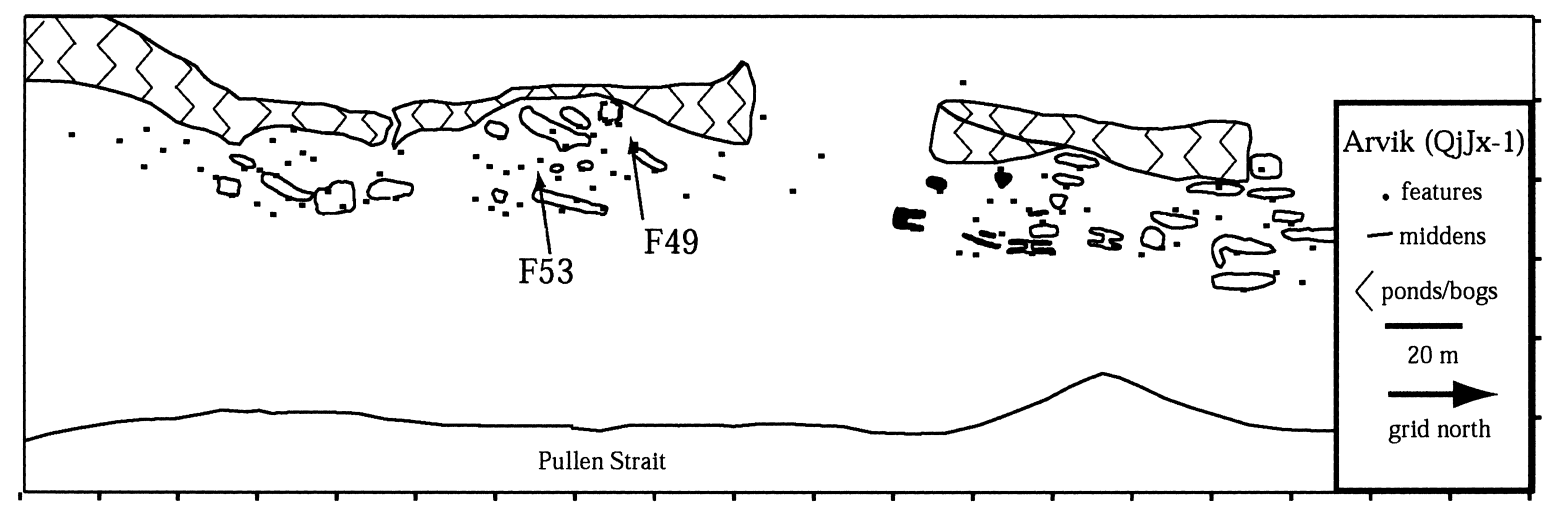

Figure 3. Plan of Arvik, showing the location of the features discussed in the text. 


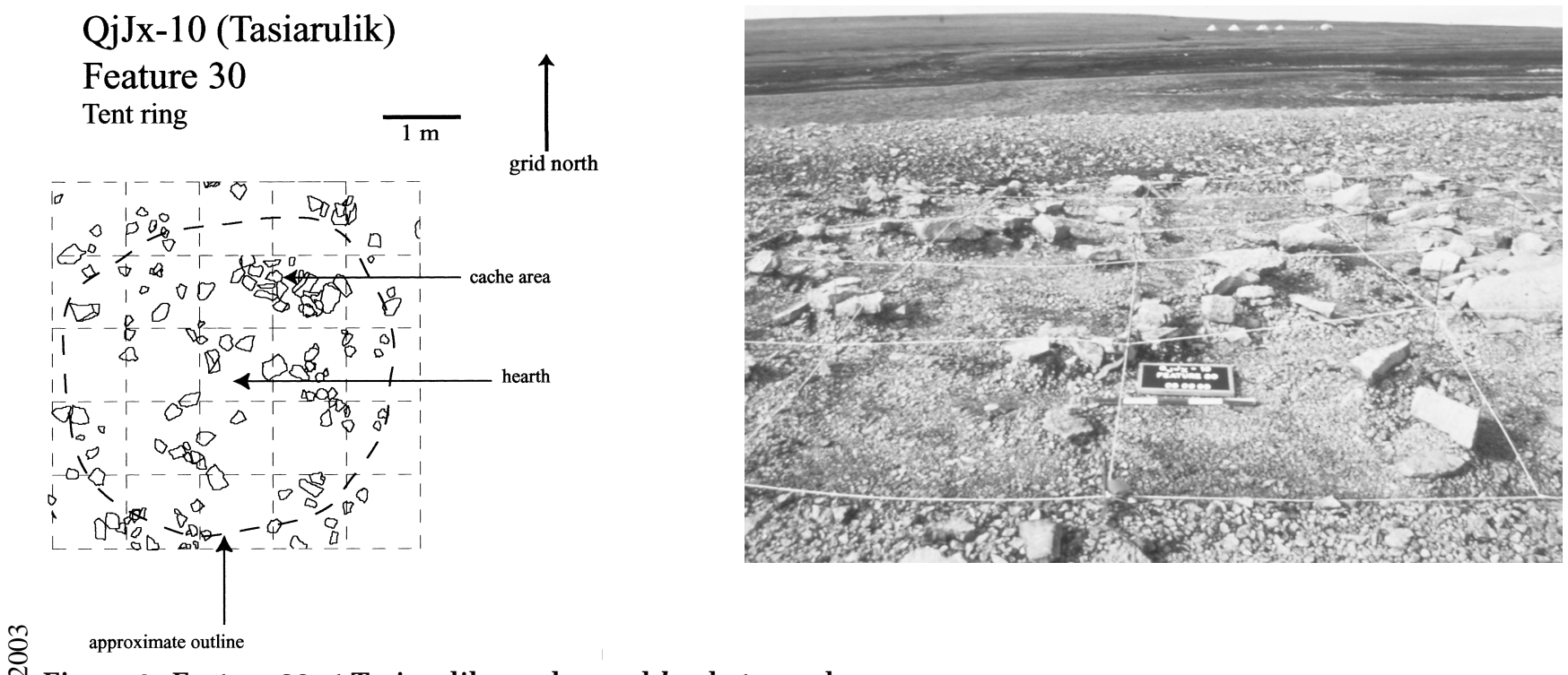

0
0
0
0
0
0
0
0
0
0
0
0
0
0
0
0
0
0
3
0
0
0
0
0
0
0
0
0
0
0
0
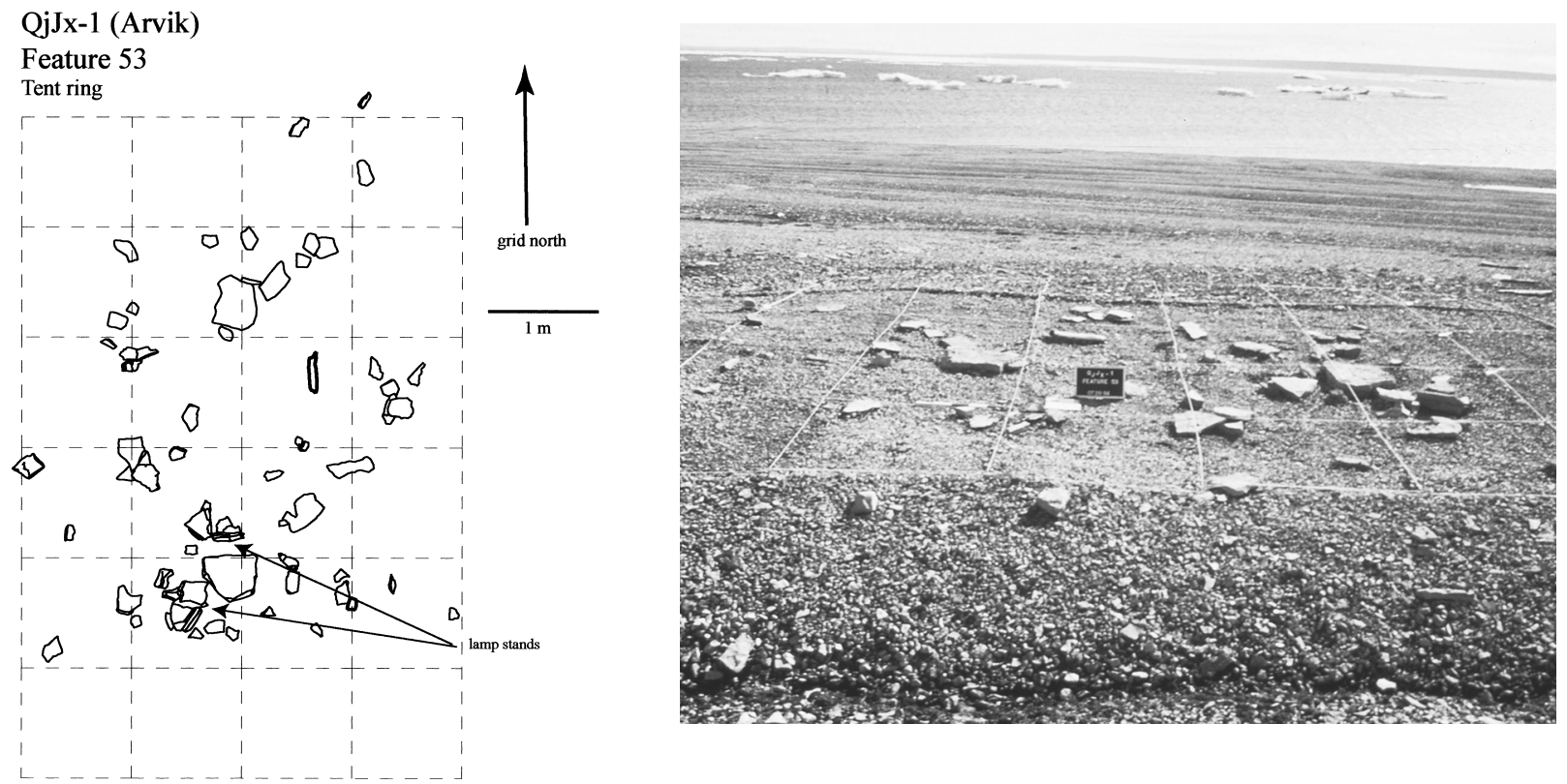

Figure 5. Feature 53 at Arvik: a, plan and b, photograph.

moved for use in other tent rings), but two hearth/lamp stand complexes were clearly visible on the surface before excavation. Each lamp stand is a large boulder with a flat, slightly dished surface reddened from heat. One is in the north half, and one in the south half of the tent ring. The southern lamp stand is distinguished by having two small hearths adjacent to it, one to the north and one to the east. Each of these is defined by two small upright slabs at right angles to each other to form a corner, with a small pavement at the base, in the angle formed by the two uprights. This pavement is lower than the surface of the adjacent lamp stand. The eastern hearth in particular contained carbonized blubber and other burnt material. The assemblage 


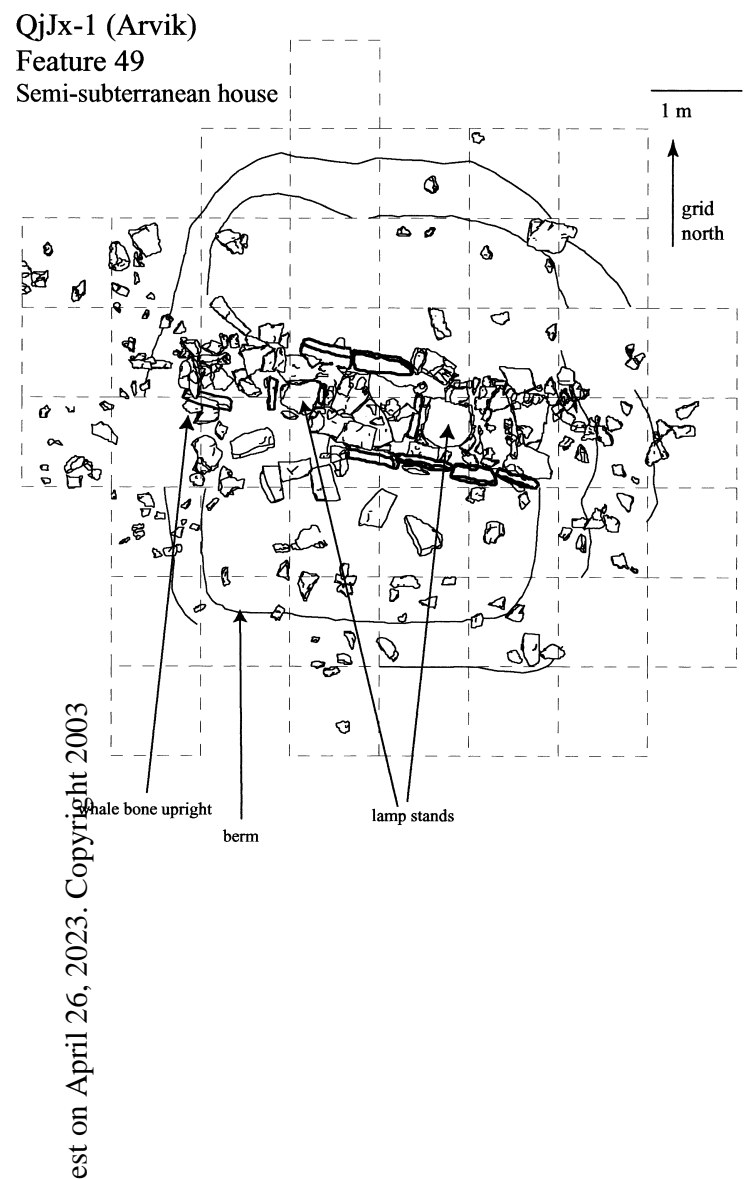

Figug 6. Feature 49 at Arvik: $a$, plan and b, photograph.

fro® Feature 53 was small, with no large concentrat:ึnns of debitage, but contained typical Late Doret objects such as a Type G harpoon head anditwo lamp fragments. There were very few faunal remains recovered, and as in Feature 30, most are bird bone.

\section{Semi-Subterranean Houses}

The best-preserved feature at any of the sites excavated on Little Cornwallis Island was a semi-subterranean house, Feature 49 at Arvik (Figure 6a-b). The house was surrounded by a low gravel berm, which had been topped by a wall of sod blocks. The interior measured $4.5 \mathrm{~m}$ square, and was bisected by a very carefully constructed, classic axial passage. As reconstructed by Bjarne Grønnow, the axial feature was built upon a foundation of fine gravel. Slabs of dolomite were used as paving stones, as uprights along both sides of the passage, and as pot supports. Some had been shaped to improve the fit. Two thicker boulders with flat sur-

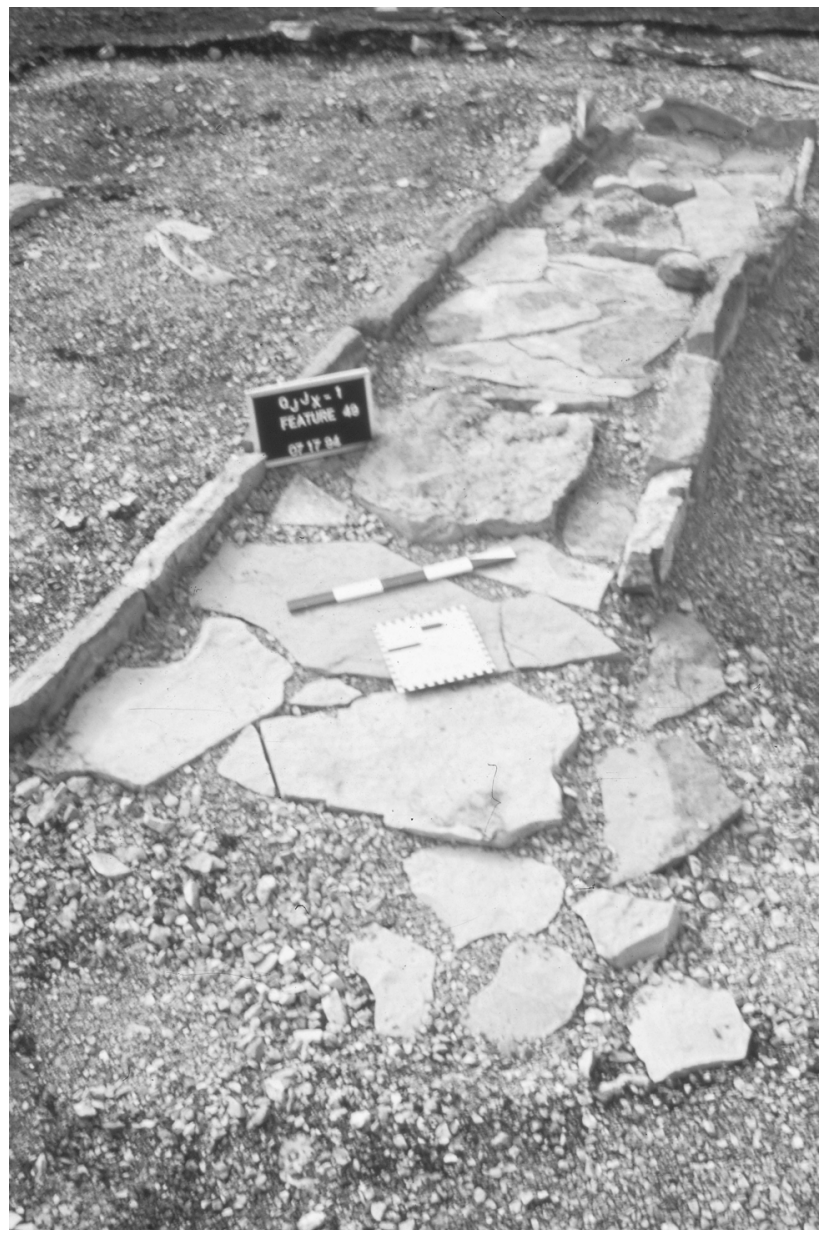

faces were placed in the axial features as lamp stands, and a third was used as an anvil. This slab was cracked and the hammer stone was still in place. At the back (inland) end of the feature was an unpaved section, defined by upright slabs, which might have been a meat locker. Behind this was the stub of a whale mandible upright, held in place by two slabs and a cobble. There is a similar axial feature at QiLa-3 (although without the whale bone), with two associated middens, the only features at the site. Of the six semi-subterranean dwellings excavated on Little Cornwallis Island, these were the only two that had classic paved axial features. The remaining houses had more or less well-preserved axial features constructed of local dolomite boulders, but with no evidence of paving, and with box hearths instead of lamp stands.

Feature 59 at Tasiarulik (Figure 7a-b), like feature 49 at Arvik, is a large axial passage structure $(4.5 \times 5 \mathrm{~m})$ surrounded by a gravel berm. Although there were no clear indications of a sod-block wall, the heavy vegetation cover prior to 


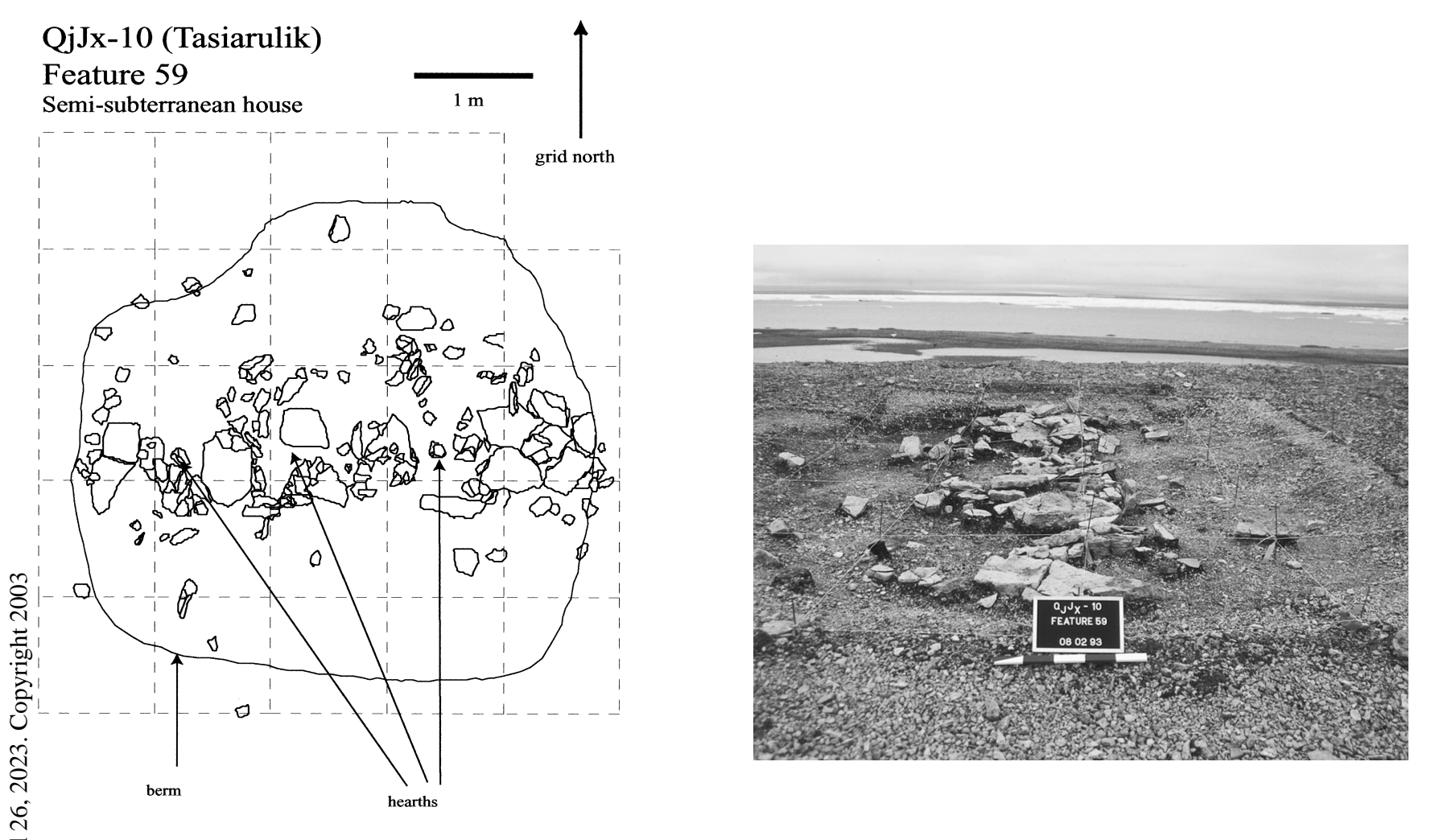

Figure 7. Feature 59 at Tasiarulik: $a$, plan and $b$, photograph.

ธี

$\stackrel{0}{\approx}$

excavation suggested one had been in place. The oxial feature, however, was not a classic mid-pas- sage. Rather it consisted of two parallel rows of Jblocky dolomite boulders spaced about one and a कू half meters apart. Three slab hearths inside this passage were identified by the red staining, with @ burned blubber and bone beneath some. The assemblage from this house included a typical range of Late Dorset tools, as well as seal, caribou, bird, and fox bones.

Dorset architecture, like all Paleoeskimo architecture, is enigmatic and poorly understood. As a recent workshop on Paleoeskimo architecture $^{1}$ demonstrated, it varies considerably across time and space, but within a fairly narrow range. Axial features are the most distinctive aspect of Paleoeskimo architecture, but our understanding of these features is limited by a lack of ethnographic analogues. Researchers rely on Inuit culture as a source of analogies when trying to understand other aspects of Paleoeskimo lifeways (such as hunting). There are considerable differences between Dorset and Inuit architecture, however, suggesting that other differences also exist. Yet, it is worth exploring the utility of this analogy from Inuit to Dorset culture on a number of levels.

\section{Use of Inuit Ethnography as an Analogue: Examples}

When Diamond Jenness first identified the Dorset culture as distinct from Thule culture in 1925 (Jenness 1925), it was obvious that despite intriguing differences, it was "an Eskimo" culture. Since then, understanding of Dorset culture has relied heavily on both explicit and implicit analogies from ethnographic Inuit culture. Such analogies are based on a number of criteria, in particular a probable common ancestor in Alaska prior to 4500 B.P. and shared environmental and economic adaptations, in that both are Arctic maritime hunter groups exhibiting a heavy reliance on sea mammals. Recently, Sheppard has used folktales to suggest that they also shared a common eskimoan language and ideology (Sheppard 1998). These similarities are balanced by significant differences, however. In particular, Thule culture, ancestral to modern Inuit society, developed as a whaling society, with complex technological and social adaptations to the communal 
hunting of large whales. Although whaling was abandoned in many Inuit communities prior to historic contact, some elements of it persisted: technologies such as large boats, umiat, and social structures relating to the organization of large communal hunts, for example. Dorset hunters lacked the technological means to hunt large whales although it is not clear whether they also lacked the social structures involved in large-scale communal hunting. Walrus hunting, one of the hallmarks of Dorset culture, probably required a significant amount of cooperation and collaboration among hunters (Murray 1996).

The most common uses of explicit analogies from Inuit to Dorset culture are in the realm of technology and subsistence: thus Dorset artifacts (most commonly harpoons and related gear) are conæ̧ pared to ethnographically known Inuit technol@gies to infer use in specific types of hunting (ice dedge vs. breathing-hole), as well as in species spegiffic identifications: walrus/large seal harpooms vs. small seal harpoons and so forth (see Maŝfwell 1985). Here analogies are most likely to be 애 firm ground: technological constraints and common (albeit distant) ancestors for these technol comparing the two, while the dramatic seasonal variation in abundance and distribution of resouthes in the Arctic argues for similar resource ext角ction strategies, within the allowances of avafiable technology.

A second frequent use of Inuit, indeed circungpolar, ethnographic data is in the interpretationg్ำf Dorset art. Here interpretation of different motifs (especially x-ray) and the meaning and assoc ${ }^{2}$ tion of specific representations (e.g., bears) are drawn from an understanding of Inuit art specifically, and circumpolar art more generally (Swinton 1967; Taylor 1967). Given the circumpolar distribution of these traits, an analogy is warranted, but more often than not the analogy stops short of considering the evident differences in the form and material of amulets for instance (LeMoine et al. 1995; but see Sutherland 2001 for an exception to this). Dorset art is characterized by finely carved figurines that primarily depict animals and people in a realistic fashion, although there is also a strong component of more abstract carvings. Many pieces are embellished with incised lines along the midline and at joints. This skeletal or x-ray motif is most likely related to beliefs that bones and joints are ritually powerful, and that the skeleton represents in some ways the essence of the being. The art is most frequently (and probably correctly) understood as an element of a shamanic/shamanistic tradition in which shamans and their animal spirit helpers act as intermediaries between the human and animal worlds. In an earlier paper (LeMoine et al. 1995) my co-authors and I argued that some Dorset art is specifically shamanic, that is, belonging to a shaman as part of his or her ritual paraphernalia, and some is shamanistic, belonging to and created by individuals as amulets. This is analogous to the Inuit case, where shamans manufactured special paraphernalia for their own use and individuals created amulets for themselves or their children and grandchildren. The two traditions are not identical, however, not the least because the form of the amulets are very different. Inuit amulets are typically made of minimally modified natural materials-bones, feathers, pieces of skin, and the like. While Dorset people may have used similar (archaeologically invisible) amulets as well, the finely carved amulets commonly found on Dorset sites are not known from Inuit culture.

Aside from these specific examples, understanding of Dorset culture is implicitly rather than explicitly informed by Inuit ethnography. (Inasmuch, I might add, as Dorset society is considered at all, for most authors confine their discussions to subsistence and technology, leaving the reader with the impression of an "Inuit-like" society without making the analogy explicit.) A good example of this is the unstated analogy to Inuit household organization. Typically a link is made between the lamp or hearth and the family: Inuit nuclear families each maintained a lamp, the property and responsibility of the wife, and when more than one nuclear family shared a house, each wife had her own lamp. The same is assumed to be true of Dorset houses and lamps (e.g., Maxwell 1985; McGhee 1981; Plumet 1985). Use of this analogy clearly has implications for understanding households, gender roles, and architecture, but it is important to make our use of it explicit, and in doing so make it simultaneously more transparent and more robust. One way to do this is to consider both the positive analogy (the similarities), and the negative analogy (the differences) (Wylie 1985). I suggest that these analogies be used both more extensively and more carefully to illuminate the differences and the similarities between Dorset and Inuit culture. Thus, although I accept that a Dorset nuclear family is represented by a lamp or hearth as an Inuit family would be, I do not assume that one can similarly transfer other elements of family or household organization from Inuit to Dorset. 
Rather, in the following sections I will consider how Inuit family and household organization are expressed in architecture and ideology, compare this to the Dorset archaeological record to evaluate the similarities and differences, and consider what this might mean in terms of Dorset groups.

\section{Gender, Households, and Architecture}

Gender, households, and architecture are closely intertwined aspects of a society, but they are not all equally recoverable in the archaeological record. Gender, as Gero has recently pointed out, is not a thing, but a "complex, composite abstraction" (Gero 2001). As such, we cannot dig it up, nor can we "read" it in any simple or direct way ठ̊ from archaeological remains. Understanding gender roles in a prehistoric society requires using multiple lines of evidence to construct arguments ôthat are inevitably open to discussion, modification, and revision, much as gender roles themธิ่ selves are in any society.

- Similarly, households, defined here as the group of individuals inhabiting a dwelling, are not lying buried in the ground waiting to be disz covered. Although more concrete than gender (or $\overrightarrow{\mathrm{s}}$ any other social) roles, since households consist $\widetilde{\mathrm{E}}_{\mathrm{O}}$ of a group of living people sharing a dwelling $\vec{\partial}$ (even if the specific membership is ephemeral), छ households are dynamic-growing, and shrinking, changing in composition on a number of đt time scales, from seasonal to generational (e.g., ¿ू David 1971 and many others). While an ideal household, with its attendant social roles, may exist in a society (think of "Leave it to Beaver"), variations (think of "My Three Sons") are so inevitable and commonplace that that the "ideal" may be more difficult to find at any point in time than are any of a number of variants. Similarly, in mobile societies especially, "ideal" household composition can vary depending with season and location. Thus the single-family Saami households described by Yates, with rigidly defined use of interior space, exist only for part of the year. At other times of year families live together, and necessarily use the same physical space differently (Yates 1989). Inuit household composition also changed seasonally, with families more likely to combine into larger households in the winter, although in this case the physical space changes too.

Inevitably, architecture is the starting point for studies of prehistoric households. Architecture provides the physical link between households, the social group of individuals resident in a dwelling, and the social roles, including gender, that these individuals act out during the course of their lives (Netting et al. 1984). Dwellings are constructed to contain the household group (in all its variants) and as such we can rightly expect that to understand the one, we need to understand the other. There has been a great deal written on the relationship of households to their dwellings, from the relatively mundane subject of how many people lived in dwellings of a particular size to the underlying ideological meaning of the arrangement of space and objects in a room and the role of architecture as a "social space," which both shapes and is shaped by social action (Bourdieu 1973), although little of it addresses the dwellings of mobile hunter-gatherers (see Tanner 1991; Whitelaw 1994 for some exceptions; Yates 1989).

Houses of all sorts potentially encode information about peoples' worldviews. Tanner (1991), looking at social space among northern Cree and Fijian communities, identifies two ends of a continuum where, at one end, social space reflects social relations in an unintended or incidental way, and at the other people expressly endow their built environment with cosmological, ritual, or social meaning. He includes as social space both the organization of a dwelling itself, and the arrangement of dwellings and other features of a camp or community, a point highlighted by Whitelaw (1994). Identifying such arrangements in an archaeological site, particularly one that has been reoccupied, is not necessarily straightforward or even always possible. Nor is it likely to be immediately obvious where a particular society lay on this continuum. Nevertheless, it is possible, by examining multiple lines of evidence, to make some headway in identifying how even ephemeral architectural remains should be interpreted.

Allison (1999:15) has suggested that rather than seeking to find "ideal" households in archaeological situations we focus on "agencies which formulate a household." In other words, we should be seeking to understand the ways in which households were constituted, and the reasons for the form they take in any particular society instead of trying to identify a "normal" or ideal family. Such an approach should make it more likely that we understand both what the "ideal" household might have been at any particular time, and why it may have been considered so. Depending on the length of time a dwelling was occupied, or the number of times it was reoccupied (as Inuit 
winter houses at least were), a dwelling may have housed any number of variations on the "ideal" family or household resulting in an accretion of information difficult to untangle.

\section{Gender and Architecture in Inuit Society}

To understand Dorset architecture in a social context, we need first to be clear about the ethnographic case we will use for the basis of our analogies. Let us begin, then, with an examination of Inuit gender roles, households, and architecture, focusing here on eastern Arctic Inuit, rather than the somewhat different Alaskan groups, although I will refer to some Alaskan material as well. Whitridge (1999) has recently demonstrated that there are direct links between eastern Arctic Inu㟲 and Alaska Inupiat social structures, and that these are mirrored in architecture.

F Among the Inuit, perhaps more than anywhe else in the world, we find the quintessential division of male (husbands) hunters out on the langeg female (wives) inside the home. This strogag association is evident in early classificationș of material culture into "men's tools" and “wợnen’s tools” (e.g., Murdoch [1892] 1988; Nelsonf1899] 1983). In the ideal Inuit world, men protide the food and raw material for clothing and tool , in the form of hunted animals, while women maiantain the home and process the animals their hus fiands bring them: butchering them, redistributing meat, and transforming the products of the hung into food and clothing. Although in practice ther is considerable situational variation, tradition Inuit recognize a strict gendered division of labs (Guemple 1986). A husband and a wife-as distinct from a man and a woman (Bodenhorn 1990)_are the minimal unit of production. Unlike some hunter-gatherer societies, such as the Numic (Whitley 1994), men's and women's roles are complementary in Inuit society-a husband and wife must work together to provide for each other and for their dependants. On a material level, to hunt without skillfully made warm and waterproof clothing is impossible. To sew such clothing without a steady supply of hides is equally impossible. Moreover, while women can (and do) hunt, and men can (and do) sew, one person cannot successfully do all the hunting and sewing required to maintain a family-there is not enough time. Although women do not generally hunt, they are frequently involved in trapping small animals such as foxes, and in fishing. Indeed, there are many well-documented cases of individual women be- ing skillful hunters of larger species (Guemple 1986). This complementary division of labor also works on the ideological level. One Iñupiat informant expressed it to Bodenhorn (1990:61) saying "I'm not the great hunter, my wife is," and making explicit the belief that animals give themselves to a hunter because their spirits have been treated well by his wife. Women (and in particular wives), in their role as seamstresses and distributors of meat, are integral to the success of a hunt. It is their hospitable treatment of an animal, by sharing its meat and turning its hide into clothing, which guarantees successful hunting in the future.

Along with this division of labor is a division of realms, with the house (inside) being most closely associated with women and the land (outside) with men. This appears to be true not only in the mundane sense that women are responsible for the operation and maintenance of the house, but in a deeper sense as well. The Inuit house, as the quintessential female structure and domain, is likened both to a womb and to a whale, (Lowenstein 1993; Oosten 1986; Saladin D’Anglure 1986), where a woman tending a lamp is tending the soul of the whale ${ }^{2}$. Further, the Inuit house appears to be the domain of the nuclear family: in many cases houses are built for single families (Jenness 1923) and when multiple families share a structure, the space assigned to each family is clearly delineated (Jenness 1923; Mathiessen 1928). Families living together in the same dwelling, however, do share some aspects of everyday life. In particular, Riches (1982:185) emphasizes that they share food and generally eat together (in spite of the multiple kitchens or lamps). He suggests "living in a multifamily household has symbolic purposes: in this behavior some sort of exclusive sociability among the co-residents is being asserted." Thus, according to Riches, Inuit families living together are reinforcing the importance of sharing, by extending community-level sharing, which may be manipulated, to the household, where hoarding and differential access to goods is impossible. Again, according to Riches (1982:185) "In living together under one roof, people communicate the special extent to which they are prepared to subscribe to the ideals of rendering support and succour."

Traditionally, much of the interior of a house was common space accessible to family members and guests alike. Sleeping space on the other hand, although visible to all in many cases, was accessible only to the family and invited guests, usually close relations (Briggs 1979; Jenness 1923, [1928] 1959.) In circumstances where multiple families shared the 
same structure (a common occurrence in winter, but not summer), sleeping spaces for each family were segregated in multi-lobed structures, even though the families might be closely related. Similarly kitchen space in multi-family homes was also segregated, sometimes in different rooms, sometimes merely on different sides of the communal living space (Balikci 1970; Briggs 1979; Mauss [1906] 1979). Peter Dawson (1995) has recently discussed the relationship between architecture, social use of space, and gender in Inuit society. In traditional Inuit houses, physical access to particular spaces (particularly kitchens) was restricted and controlled by women. Dawson (1995) relates this to the significant role of women in the home, and the home as both the source of and symbol of her role in the society. However, Whitridge (1999) identifies separate \&્d kitchen spaces as restricting the social role of W women by sequestering them, when most important Fond public activities take place in a men's house. òmen's houses are identified with whaling crews, and are known prehistorically from Classic Thule ऽิ่ sites, and in some areas into the historic period.

ช. The social implications of these gender and architectural relations are varied. The nuclear family as traditionally defined is the basic unit of proofduction and reproduction, but production and $\overrightarrow{\mathrm{s}}$ redistribution invariably create many links be$\widetilde{\Xi}_{0}$ tween families. Sometimes these links are exs.pressed architecturally, especially during times of E resource stress, according to Schledermann (1976), but not always. Whitelaw (1994) suggests that the Ds spatial organization of groups of structures maps ङ kin, and therefore redistributive relations, rather than interior architecture. Whitridge (1999) similarly links house groups at Thule whaling sites to extended families. Interestingly, communal or cooperative production (i.e., beyond the nuclear family) is more often an element of men's labor than women's in traditional society: men hunt together, often in family-based groups such as brothers, brothers-in-law, or cousins, but women's traditional productive activities are often carried out more or less independently, if not actually alone: preparing hides, sewing clothes, cooking food, etc. In Alaskan Iñupiat society, and in some parts of the eastern Arctic this is reflected in the men's house or karigi, where men gather, and where important rituals are often enacted. It is, perhaps, this independence, the individual nature of the most important of women's tasks, which is reflected in the nuclear family focus of traditional Inuit architecture. Note that this is not meant to imply that women work alone. Women frequently work together, but their work does not require them to be together and often can just as easily be done on a smaller scale by a single person.

One striking element of this productive system in Iñupiat (Alaskan) and by extension, Inuit society, is the ritual requirement that a wife sew the clothes that her husband wears while hunting. This is an integral part of the ritual and symbolic side of hunting, as part of the expectation that the souls of animals will be treated hospitably, as seen in tasks including the distribution of meat and sewing of clothing: two of a woman's most important activities (Bodenhorn 1990).

In Inuit society, then, we find a situation of complementary gender roles where women are strongly associated with houses, and houses are conceptualized as both wombs and whales. The products of both men's and women's labor is vital to the survival of a family, and neither can be successfully completed without the work of both. Materially, it is possible to link tools associated with hunting with male roles, and those associated with the house and sewing with female roles. This is a necessarily generalized view and obscures the fact that both sexes can do, and sometimes are required to do, the work of the opposite sex. When women do men's work, or vice versa, there is clear recognition that they are doing so, however, reinforcing the idea of a gendered division of labor even as the rules are breached.

\section{Gender and Space in Dorset Society}

How does this compare with the Dorset case? On the most basic level, it is reasonable to assume that the basic gendered division of labor known from Inuit society can be projected backwards to the Dorset, and to all Paleoeskimo groups. The associations of women with homes and the production of clothing are strong in all northern societies. Conkey (1991) and, more recently, Soffer et al. (2000) even push the link between women and sewing back to the Paleolithic, suggesting that it has very great time-depth. With a similar technology and in the same environment, one requiring warm clothing, we can assume that the same sorts of tasks (sewing and hunting as the most important) needed to be done, and that the basic roles assigned to men and women were probably similar to those described for the Inuit.

Can we go from this basic analogy to one in which the role of women as seamstresses and their role in the home is seen as a vital element of hunting, where women in effect tend the souls of 
hunted animals? This link is more tenuous, but there are a number or lines of evidence that suggest that this was the case. We have established that Dorset belief systems were rooted in the same circumpolar shamanism as Inuit (LeMoine et al. 1995; Sutherland and McGhee 1997), very likely with ancient roots in Siberia (Gulløv and Appelt 2001; Sutherland 2001). Thus, like other circumpolar groups, Dorset people were concerned with maintaining social relationships with the spirits of the animals they hunted. Skeletal motifs on Dorset carvings indicate that like Inuit and ethnographic Siberian cultures, the Dorset saw joints and the skeleton, particularly the mid-line, as spiritually powerful, an enduring physical locus of the spirit. Carvings and shamanic paraphernalia suggest that mediation bet栗een the two worlds worked at two levels, witt both specialist shamans and lay individuals hav the celationship between an animal and a hunter are Yess easy to confirm. Certainly this aspect of Inu解 ideology has ancient roots, as it is found amoुg all the speakers of Eskimoan languages (Boḍlenhorn, 1990; Fienup-Riordan 1990:191), and Dorget society men and women had complementaryseroles both in the economic sense and in the idechogical sense. This is not to say, however, that the societies were identical. The archaeological f్cocord reveals striking differences between the wo ing Eetween the hunter and the hunted.

\section{Comparing Dorset and Inuit Architecture}

Differences between historic Inuit and Dorset houses include the house shape, interior arrangement, and aspects of the construction. The most obvious difference is the presence of the axial passage in Dorset structures, which has implications for the shape of the house, the organization of space within the house, and household organization. Axial features are one of the defining characteristics of Paleoeskimo architecture-the central area of a house or tent typically consists of two parallel rows of upright slabs. The space between the slabs is sometimes paved and usually contains hearths, hearth boxes, or lamp stands and pot supports. The areas on either side of the axial feature are generally thought to have been living/sleeping areas. They are sometimes also paved (Plumet
1985, 1998) and are sometime associated with moss or heather mats (McGhee 1981).

Axial features were the focus of much interior activity. The presence of hearths or lamp stands indicates that they were the locus of heating and lighting, cooking, and drying of clothing. Concentrations of debitage and artifacts, and elements such as the large anvil stone still in situ in Feature 49 at Arvik, suggest that other activities also were focused around axial features (McGhee 1981; Plumet 1985). As in many societies, the hearth itself was likely also laden with meaning. Axial features are also known from other northern cultures. Similar (although not identical) structures are known from elsewhere, as for example, among the Saami (Knuth 1967; Yates 1989) where the different parts of the tent were apportioned on the basis of age and gender, and had important symbolic meaning.

During the Dorset period, axial features are associated with both what are thought to be semisubterranean cold-season dwellings and warm-season tent rings. Cold-season houses are usually only slightly subterranean, like those on Little Cornwallis Island, sometimes with evidence for low sod or stone walls. A superstructure of driftwood or even whalebone probably supported a hide roof, which may have also been covered with sod and/or snow. Tent rings are identified by the boulders which held down the bottom of the hide tents, although these are rarely all present and in some cases may be completely absent, having been removed for reuse. Axial features are less frequently found in warm- season dwellings. When they are absent, hearths (or lamp stands) are often present, and like mid-passages, seem to have been the focus of much activity, including the manufacture of tools from wood, bone, antler, ivory, and copper, as indicated by quantities of tiny fragments of these materials found in association with them. Feature 30 at Tasiarulik is a good example of such a tent ring.

As noted above, Inuit families (frequently equivalent to households) were focused on the cooperating unit of a husband and wife and their dependants. When families shared houses, prehistoric and historic Inuit houses were designed so that each family had a space of its own, physically distinct from the spaces of other families, often in separate lobes of the house. Kitchen areas were sometimes also distinct. An axial passage similarly creates separate spaces in a house, but only two, one on either side. If we accept that each hearth or lamp stand represents one family 
(also a husband and wife and their dependants), then many Late Dorset houses, with two, or sometimes even three lamp stands housed two or more families. Since there is no indication of segregation by sex in any of these houses, the most cautious explanation is that each family occupied one side of the house. When more than two families shared a house, perhaps the two more closely related shared one side. Yates (1989) describes a similar situation for shared Saami tents, where each family occupied one side of the tent (although the use of space was different when only one family occupied a tent). It is of course possible that age and sex determine where Dorset family members slept within their own area, but currently we have no data to discern such behavior. A key difference between Inuit and Dorset houses is ¿्లt that Dorset families appear to have shared the priD mary workspace of the house, the axial passage, .o where lamps or hearths were located. This sugôtgests that families sharing Dorset axial feature dwellings were more tightly integrated than Inuit ¿ิ families sharing multi-lobed winter houses, or at -least felt the need (not necessarily on a conscious level) to reinforce the unity of the multi-family household by more closely integrating symboli§. cally-charged tasks such as maintaining the lamp $\overrightarrow{\mathrm{s}}$ or fire. According to Riches' (1982) understanding E⿱ ${ }_{0}$ of multi-family households, it would also suggest ot that they were reinforcing and emphasizing the Iimportance of community-wide sharing of food. Seasonal differences in household organizadion between Dorset and Inuit culture indicate that closely integrated households incorporating multiple families were of greater significance in Dorset times. As noted above, in many regions Inuit families moved from multi-family winter dwellings to single-family tents during the summer. Evidence from tent rings on Little Cornwallis Island indicates that this was frequently not the case for Dorset families. One of the best-preserved tent rings excavated on Little Cornwallis Island has multiple hearths, indicating that two families shared the tent. Other less well-preserved examples also seem to have had multiple hearths. Some axial feature dwellings with multiple hearths, such as those excavated by McGhee on Dundas Island, seem to be summer dwellings too, and three of eight Early Dorset tent rings excavated by Helmer on Kavilik Island also had two hearths. Further afield in Ungava, Plumet (1998) describes tent structures with multiple hearths, often on the periphery of the structure. I would argue then, that while (nuclear) families may have been constituted in the same way in Inuit and Dorset society, households were conceived of somewhat differently, and Dorset households were more frequently, perhaps even usually, made up of more than one nuclear family.

It cannot be said that links between families are unimportant in historic Inuit society, but neither can it be denied that as an economic unit, an isolated nuclear family could survive on its own for many months if need be. In Dorset society, the different household organization suggests that different methods of hunting, seasonal use of resources, and/or mechanisms for sharing resources (including labor) existed, although the form these might have taken is not apparent at this time. The result was that nuclear families less frequently acted independently.

Households usually pool resources (Wilk and Netting 1984), but little work has been done to clarify how and when this household form becomes important. The fact that at all times of the year Dorset families shared dwellings suggests that the basic unit in Dorset society was somewhat larger than the nuclear family: minimally two families. (Sharing between houses also took place, but the workings of this process are not apparent at this time.) One of the implications of this is that women's labor may have been organized differently in Dorset than in Inuit times. Exactly how it was organized is difficult to say precisely, but one possibility is that cooperative work by women was quite important. This would result from the close relationship between families sharing a dwelling. In contrast, in Inuit society, some of the most important roles of a woman require that she complete tasks, such as the sewing of her husband's (and her family's) clothing, on her own. Other tasks may be shared, but for the most part are not: women produce their own fuel, process meat hunted by their husbands, distribute that meat, etc. Without considering any ritual significance (although there surely was some), I suggest that the work of Dorset women was organized somewhat differently.

Riches (1982) suggests that multi-family households in Inuit society existed primarily to reduce risk of food shortage-insuring, both in real terms and symbolically, that resources were distributed both between and among nuclear families. Still, sharing a dwelling may have other benefits as well-unintended consequences perhaps, but important all the same. Sharing a dwelling would reduce fuel needs, and the necessity for each 
woman to gather enough fuel to heat her own house, thus allowing more time for other activities. It may also have made it easier to share childcare, giving women more time to participate in activities outside the home, such as fishing and trapping (Peacock 1991). In order for Late Dorset people to have repopulated the High Arctic after a long period of abandonment, their population must have grown substantially from its Middle Dorset size. A number of factors, including the number of children born, the number of children who survive, and the balance of immigration and emigration, affect population growth rates, but lacking skeletal material, it is virtually impossible to identify which (if any) of these factors affected Dorset populations (Bentley 1996). There is no evidence for immigration on a large scale, so it seems like⿻ bination of increased birth rates and decreased mortality rates. Either of these could affect or be affeढ़ted by childcare and other activities of women.

ปิ There is evidence across the High Arctic that smâtler animals (birds, foxes, fish, and rabbits) werệ taken in greater numbers during Late Dorset tharin earlier periods (Darwent 2001). These are the gorts of species that are typically hunted not just erlyâpeople (Brumbach and Jarvenpa 1997). Increased use of these species is linked to reduced resiffential mobility and higher population density idesifify a causal relationship. Reduced residential molgllity and associated higher population density are ossible because the resource base is expanded whô small game are considered acceptable food. In the High Arctic at least, use of these species is also necessary as residential mobility decreases and population density rises, because more "highly ranked" species such as caribou and muskox cannot support the greater hunting pressure associated with these developments (Darwent 2001). Women may have found that increased reliance on these smaller species, along with an increased need to supervise small children, required more sharing of labor (Peacock 1991).

A second factor is also tied to reduced mobility. Small game species, although used in greater numbers, were not the mainstay of the Late Dorset economy. People still relied heavily on sea mammals, particularly ringed seal but also walrus and other species. (Caribou was also important in many parts of the Arctic during Dorset times, but not in the High Arctic [Darwent 2001;
Mary-Rousselière 1984; Plumet 1998].) Ethnographically, these animals are typically hunted by men, either singly or, more often, in small (for the hunting of seals) to large (for walrus) groups. Using the same logic that links prehistoric women with tasks such as sewing, we can assume that Late Dorset men too, were primarily responsible for hunting large mammals. Where permanent or semi-permanent dwellings, such as Late Dorset semi-subterranean houses, are located at some distance from preferred hunting locations, it is not uncommon for men to go alone to such locations, leaving other family members behind for days or weeks at a time (Briggs 1979; Janes 1983). Those who stay at home can rely to some extent on stored food, but probably also fish or hunt for themselves. Again, this may contribute to the need for women to share work.

In this sense, the axial feature, which divides a house in two, also can be seen as unifying it-a physical structure that reinforces the unity of a household made up of two or more cooperating families. As Plumet (1998) has argued, axial features, then, can be likened to the central line of a skeletal motif-the soul of the house, constructed in stone and housing the essential hearths/lamp stands tended by the women of the house. Their presence as shared space in multifamily households acts as a reminder of the necessary and essential unity of those households. This line of thought brings to light a further similarity between Inuit and Dorset houses: the house in both cases is a metaphor for the spiritual animals on which life depended.

\section{From Axial Features to Long Houses}

Plumet (1998) has already pointed out that this argument can be taken one step further. In Late Dorset times, particularly in newly reoccupied areas of the far North, Dorset communities constructed large communal structures known as longhouses. Most authors agree that they represent seasonal aggregation sites. Longhouses are identified as long narrow structures with low stone walls. They range from $8-45 \mathrm{~m}$ long, but most are in the 12-14 $\mathrm{m}$ range (Damkjar 2000) and may have housed as many as 10-12 families. They were used in summer or fall, and were probably not roofed, although it is possible a line of tents was erected within them, probably open to each other (Damkjar 2000; Plumet 1985; Schledermann 1990). Longhouses often have a row of hearths or 
other features along the midline. Plumet (1985; 1998) describes an interesting example that has two major hearths at either end of the long axis of the long house, with individual hearths in opposing niches along the outside walls. Long house sites are frequently associated with rows of external hearths. These come in a variety of forms, and often more than one form is found at a single site (e.g., the David Site [Appelt 1999]). In general they are made up of conjoined hearths or lamp stands, sometimes associated with meat caches or storage lockers. They are, in a sense, extended axial features (see also Gulløv and Appelt 2001). If we apply the metaphor of a skeletal motif to these as well, then it is evident that they are the physical manifestation of community unity-the locus of the spirit or soul of the social group, which comes ¿્ together each year to engage in ceremonies, trade, $\nexists$ and other essential social transactions. Thus Do Dorset communities expressed their relationships ôto each other and to the animal spirits on which they depended through architecture, in summer ¿ุ่ and winter multi-family dwellings, and in sea๑̊s sonal aggregation sites.

근 $\quad$ This raises some interesting questions, for although axial feature dwellings are common across the Arctic from the time of the first Paleoeskimo $\overrightarrow{\mathrm{s}}$ inhabitants until the disappearance of Dorset culङ્oture, long houses and external hearth rows appear əิprimarily in Late Dorset sites, and are most common in areas away from those where Middle Dorset communities existed between the periods Dु of High Arctic occupation. Does this insight into o the meaning of axial features help us understand why Late Dorset people began constructing hearth rows? Does the link between women and hearths have any bearing on changing women's roles or changing gender relations? The development of hearth rows out of axial features in Late Dorset is perhaps related to the extensive long-distance relationships Late Dorset people seem to have prized. As a metaphor for a unified community, the hearth rows would have been strong symbolic reminders of relationships with people seen infrequently, but who might have been vital to survival. The hearth rows would represent groups of people who actually interacted face-to-face.

As Late Dorset people reoccupied the High Arctic, maintaining relationships with what must, initially at least, have been scattered neighbors would have been important, for a whole host of social as well as economic reasons, from arranging marriages and other alliances to trading. These relationships can be seen as a sort of "in- surance," although I consider it unlikely that they operated on the very broad regional scale suggested by Murray (1996). On a more local scale, they would have been an important aspect of life expressed in a familiar metaphor.

Axial features themselves, and the social relationships they imply on a household level, are the earliest architectural form documented in the eastern Arctic. As such, their importance in Late Dorset architecture suggests not change, but continuity and development. Thus despite changes in hunting practices, for instance, ideas about the importance of houses and hearths, as well as the symbolic link between the house/hearth, women, and animal prey, remained basically the same throughout the Paleoeskimo period.

\section{Conclusions}

Using an analogy from Inuit society, we have seen that Late Dorset families and households organized themselves slightly differently, putting greater emphasis on multi-family households, than did either their Paleoeskimo ancestors or later Inuit groups. Like Inuit however, who metaphorically dwelt in whales, Dorset people probably conceptualized their homes as animals, with hearths tended by women as they tended the souls of the animals their husbands hunted. This worldview is expressed in the quintessential Paleoeskimo architectural element, the axial feature. Late Dorset families used this central feature to represent a "life-line," like the skeletal motif seen on their carvings of animals. As such it was central to the being (dwelling) and served to unify the family/families that inhabited it, both symbolically and in a very real sense, as they shared the common workspace. During the Late Dorset period, High Arctic immigrants extended this metaphor to communal gathering sites, where axial features become hearth rows and whole communities were brought together to reinforce vital social bonds. Women, as keepers of the hearth, played a vital role in keeping households and indeed whole communities together.

This strategy, of reinforcing central tenets of the Paleoeskimo ideological system in both domestic and communal/ceremonial architecture while simultaneously altering the day-to-day living situations of families and households, can be understood in the context of other changes that occurred in Late Dorset society at the same time. Riches (1982) identifies shared households as a 
risk-reducing mechanism. Groups expanding into the High Arctic during the Late Dorset period probably faced a high degree of risk as they moved into empty territory. They coped by elaborating on familiar cultural patterns, simultaneously preserving and transforming their society.

Acknowledgments. The fieldwork described in this paper was supported by a Social Sciences and Humanities Research Council of Canada grant to James Helmer and Genevieve LeMoine (No. 40192-0285); by the Polar Continental Shelf Project, Department of Energy Mines and Resources; by the Northern Scientific Training Program, Department of Indian and Northern Affairs; and by Cominco (Polaris Mine Operation) Limited. I am grateful to Scott MacEachern, Susan Kaplan, and the participants in the Palaeoeskimo Architecture wo shop of 2002 for their comments and stimulatipg conversations.

\section{End Notes}

1. '象alaeoeskimo Architecture: The State of Knowledge." September 2-6, 2002, St. Pierre, France. Organzzed by Sylvie LeBlanc and Murielle Nagy.

2. 在her dwelling types may have been associated witle other uses. In 1973, reknown Inuit artist Pud@o drew a shaman's tent in the form of a caribouf(Karsh 1977).

\section{References Cited}

Alli:ึّon, Penelope $\mathrm{M}$.

199 Introduction. In The Archaeology of Household Activities. P. M. Allison, ed. Pp. 1-18. London: Routledge.

Appelt, Martin and Hans Christian Gulløv (eds.)

1999 Late Dorset in High Arctic Greenland: Final Report of the Gateway to Greenland Project, vol. 7. Copenhagen: Danish Polar Center.

Babb, T. A. and L. C. Bliss

1974 Susceptibility to Environmental Impact of the Queen Elizabeth Islands. Arctic 27:234-237.

Balikci, Asen

1970 The Netsilik Eskimo. Garden City: The Natural History Press.

Bentley, Gillian R.

1996 How Did Prehistoric Woman Bear "Man The Hunter"? Reconstructing Fertility From The Archaeological Record. In Gender and Archaeology. R. P. Wright, ed. Pp. 23-51. Philadelphia: University of Pennsylvania Press.

Bodenhorn, Barbara

1990 “I'm Not The Great Hunter, My Wife Is": Iñupiat and Anthropological Models Of Gender. Études/Inuit/Studies 14(1-2):55-74.

Bourdieu, Pierre

1973 The Berber House. In Rules and Meanings. M. Douglas, ed. Pp. 98-110. New York: Penguin.

Briggs, Jean

1979 Never in Anger. Cambridge: Harvard University Press.

Brumbach, Hetty Jo and Robert Jarvenpa

1997 Woman the Hunter: Ethnoarchaeological Lessons from Chipewayan Life-Cycle Dynamics. In Women in Prehistory: North America and Mesoamerica. C. Claassen and R. A. Joyce, eds. Pp. 17-32. Philadelphia: University of Pennsylvania Press.

Conkey, Margaret W. (ed.)

1991 Contexts of Action, Contexts for Power: Material Culture and Gender in the Magdalenian. In Engendering Archaeology: Women in Prehistory. J. M. Gero and M. W. Conkey, eds. Pp. 57-92. Oxford: Basil Blackwell Ltd.

2001 Epilogue: Thinking about Gender with Theory and Method. In Gender in Prehispanic America. Symposium at Dumbarton Oaks, October, 1996. C. F. Klein, ed. Pp. 362. Washington, D.C.: Dumbarton Oaks Research Library and Collection.

Damkjar, Eric

2000 A Survey of Late Dorset Longhouses. In Identities and Cultural Contacts in the Arctic. M. Appelt, Joel Berglund, and Hans Christian Gulløv, eds. Pp. 170-180. Copenhagen: The Danish National Museum and Danish Polar Center.

Darwent, Christyann Marie

2001 High Arctic Palaeoeskimo Fauna: Temporal Changes and Regional Differences. Ph.D. dissertation, Department of Anthropology, University of Missouri.

David, Nicholas

1971 The Fulani Compound and the Archaeologist. World Archaeology 3(2):111-131.

Dawson, Peter C.

1995 "Unsympathetic Users": An Ethnoarchaeological Examination of Inuit Responses to the Changing Nature of the Built Environment. Arctic 48:71-80.

Dunbar, M. and K. R. Greenaway

1956 Canada from the Air. Ottawa: Queen's Printer.

Fienup-Riordan, Ann

1990 Eskimo Essays. New Brunswick: Rutgers University Press.

Gero, Joan M.

2001 Field Knots and Ceramic Beaus: Interpreting Gender in the Peruvian Early Intermediate Period. In Gender in Prehispanic America. 
Symposium at Dumbarton Oaks, October, 1996. C. F. Klein, ed. Pp. 15-55. Washington, D.C.: Dumbarton Oaks Research Library and Collection.

Guemple, Lee

1986 Men and Women, Husbands and Wives: The Role of Gender in Traditional Inuit Society. Études/Inuit/Studies 10(1-2):9-24.

Gulløv, Hans Christian and Martin Appelt

2001 Social Bonding and Shamanism among Late Dorset Groups in High Arctic Greenland. In The Archaeology of Shamanism. N. Price, ed. Pp. 146-162. London: Routledge.

Helmer, James W.

1989 Archaeological Survey of Little Cornwallis and Truro Islands, 1989. Ottawa: On file with the Archaeological Survey of Canada.

§ิ1991 Final Report of the Polaris Archaeological Research Project. Report submitted to Cominco Ltd. Polaris Mine Operation, the Archaeological Survey of Canada, Ottawa and the Prince of Wales Northern Heritage Centre. Yellowknife: Prince of Wales Northern Heritage Centre.

¿ิ่ Helmer, James W., Genevieve LeMoine, and Donald T. ๑ Hanna

Central High Arctic Archaeology (CHAAP): Report of the 1992 Field Season. Yellowknife. On file with the Prince of Wales Northern Heritage Centre.

$\overrightarrow{0}$ 1995a Report on Excavations at QjJx-10 (Tasiarulik), Little Cornwallis Island, Northwest Territories, 1993. Yellowknife. On file with the Prince of Wales Northern Heritage Centre.

1995b Report on the 1994 Excavations at Arvik (QjJx1), Little Cornwallis Island, Northwest Territories. Yellowknife. On file with The Prince of Wales Northern Heritage Centre.

Hillier, Bill and Julienne Hanson

1984 The Social Logic of Space. Cambridge: Cambridge University Press.

Janes, Robert R.

1983 Archaeological Ethnography among Mackenzie Basin Dene, Canada. Calgary: Arctic Institute of North America.

Jenness, Diamond

1923 Report of the Canadian Arctic Expedition 1913-1918 Volume XII: The Cooper Eskimos, part A, The Life of the Copper Eskimos. Ottawa: King's Printer.

1925 A New Eskimo Culture in Hudson Bay. Geographical Review 15:428-437.

[1928] People of the Twilight. Chicago: University of 1959 Chicago Press.

Karsh, Estrelita

1977 Shamans and Spirits: Myths and Medical Symbolism in Eskimo Art. Ottawa: National Museum of Man.
Knuth, Eigil

1967 Archaeology of the Musk-ox Way. Paris: Ecole Pratique Des Hautes Études, Sorbonne.

LeMoine, Genevieve, James Helmer, and Bjarne Grønnow

In Late Dorset Architecture on Little Cornwallis press Island. Études/Inuit/Studies.

LeMoine, Genevieve, James Helmer, and Donald Hanna 1995 Altered States: Human-Animal Transformational Images in Dorset Art. In The Symbolic Role of Animals in Archaeology. K. Ryan and P. J. Crabtree, eds. Pp. 38-49. MASCA Research Papers in Science and Archaeology, vol. 12. Philadelphia: The University Museum of Archaeology and Anthropology, University of Pennsylvania.

Lowenstein, Tom

1993 Ancient Land: Sacred Whale, the Inuit Hunt, and Its Rituals, vol. 189. New York: Farrar, Straus, and Giroux.

Lyons, Dianne

1982 Regionalism of Dorset Art Style: A Comparative Analysis of Stylistic Variability in Five Dorset Art Samples. Master's thesis, University of Calgary.

Mary-Rousselière, Guy

1984 Une rémarquable industrie dorsetienne de l'os caribou dans le nord de Baffin. Études/Inuit/Studies 8(2):41-59.

Mathiessen, Therkel

1928 Material Culture of the Iglulik Eskimos. In Report of the Fifth Thule Expedition 1921-1924, vol. 6(1). Copenhagen.

Mauss, Marcel

[1906] Seasonal Variation of the Eskimo: A Study in

1979 Social Morphology. London: Routledge and Kegan Paul.

Maxwell, Moreau S

1985 Prehistory of the Eastern Arctic. New York: Academic Press.

McGhee, Robert

1981 The Dorset Occupations in the Vicinity of Port Refuge, High Arctic Canada. In National Museum of Man Mercury Series, Archaeological Survey of Canada Paper, vol. 105. Ottawa: National Museum of Man.

Moore, Henrietta

1994 A Passion for Difference: Essays in Anthropology and Gender. Bloomington: Indiana University Press.

Murdoch, John

[1892] Ethnological Results of the Point Barrow

1988 Expedition. Washington, D.C.: Smithsonian Institution Press.

Murray, Maribeth

1996 Economic Change in the Palaeoeskimo Prehistory of the Foxe Basin, N.W.T. Ph.D. dissertation, Department of Anthropology, McMaster University. 
Nelson, Edward William

[1899] The Eskimo about Bering Strait. Washington,

1983 D.C.: Smithsonian Institution Press.

Netting, Robert McC., Richard R. Wilk, and

Eric J. Arnould

1984 Introduction. In Households: Comparative and Historical Studies of the Domestic Group. R. M. Netting, R. R. Wilk, and E. J. Arnould, eds. Pp. xiii-xxxviii. Berkeley: University of California Press.

Oosten, Jaarich G.

1986 Male and Female in Inuit Shamanism. Études/ Inuit/Studies 10:115-132.

Peacock, Nadine R.

1991 Rethinking the Sexual Division of Labor: Reproduction and Women's Work among The Efe. In Gender at the Crossroads of Knowledge: Feminist Anthropology in the Postmodern Era. M.

oิ di Leonardo, ed. Pp. 339-360. Berkeley: University of California Press.

Plựnget, Patrick

198㰺 Le Site de la Pointe aux Bélougas (Qilalugarsiuvik) et les maisons longues Doresétiennes. Volume 18. Montreal: Collection PaleoQuebec.

199£ Tuvaaluk, expédition multimédia dans la préhistoire du Nunavik

http://www.unites.uqam.ca/tuvaaluk/accueil/ menu2accueil.html, June 6, 2002.

Rich商s, David

198 Northern Nomadic Hunter-Gatherers. London: Academic Press.

Salą̆ in D’Anglure, Bernard

1986 Du foetus au chamane: la construction d'un "troisieme sexe” Inuite. Études/Inuit/Studies 10:25-114.

Sch dermann, Peter

197@ The Effect of Climatic/Ecological Changes on the Style of Thule Culture Winter Dwellings. Arctic and Alpine Research 8:37-47.

1990 Crossroads to Greenland: 3000 Years of Prehistory in the Eastern High Arctic, Calgary: Arctic Institute of North America, University of Calgary.

Sheppard, William L.

1998 Population Movements, Interaction, and Legendary Geography. Arctic Anthropology 35(2):147-165.

Soffer, O., J. M. Adovasio, and D. C. Hyland 2000 The "Venus" Figurines: Textiles, Basketry, Gender and Status in the Upper Paleolithic. Current Anthropology 41(4):511-537.

Sutherland, Patricia

2001 Shamanism and the Iconography of Palaeo-

Eskimo Art. In The Archaeology of

Shamanism. N. Price, ed. Pp. 135-145.

London: Routledge.
Sutherland, Patricia and Robert McGhee

1997 Lost Visions, Forgotten Dreams. http://www. civilization.ca/archeo/paleoesq/peexheng.html, May 20, 2002.

Swinton, George

1967 Prehistoric Dorset Art: The Magico-Religious Basis. The Beaver 298:32-47.

Tanner, Adrian

1991 Spatial Organization in Social Formation and Symbolic Action: Fijian and Canadian Examples. In Social Space: Human Spatial Behaviour in Dwellings and Settlements, Proceedings of an Interdisciplinary Conference. O. Grøn, E. Engelstad, and I. Lindblom, eds. Pp. 21-39. Odense: Odense University Press.

Taylor, William E., Jr.

1967 Prehistoric Dorset Art: The Silent Echoes of Culture. The Beaver 298:32-47.

Tringham, Ruth

1991 Households with Faces: The Challenge of Gender in Prehistoric Architectural Remains. In Engendering Archaeology: Women and Prehistory. J. M. Gero and M. W. Conkey, eds. Pp. 93-131. Oxford: Blackwell.

Whitelaw, Todd M.

1994 Order without Architecture: Functional, Social, and Symbolic Dimensions in HunterGatherer Settlement Organization. In Architecture and Order: Approaches to Social Space. M. P. Pearson and C. Richards, eds. Pp. 217-243: London: Routledge.

Whitley, David S.

1994 By the Hunter, For the Gatherer: Art, Social Relations, and Subsistence Change in the Prehistoric Great Basin. World Archaeology 23(3):356-372.

Whitridge, Peter James

1999 The Construction of Social Difference in a Prehistoric Inuit Whaling Community. Ph.D. dissertation, Department of Anthropology, Arizona State University.

Wilk, Richard R. and Robert McC. Netting

1984 Households: Changing Forms and Functions. In Households: Comparative and Historical Studies of the Domestic Group. R. M. Netting, R. R. Wilk, and E. J. Arnould, eds. Pp. 1-28. Berkeley: University of California Press.

Wylie, Alison

1985 The Reaction against Analogy. In Advances in Archaeological Method and Theory. M. B. Schiffer, ed. Pp. 63-111, vol. 8. Orlando: Academic Press.

Yates, Timothy

1989 Habitus and Social Space: Some Suggestions about Meaning in the Saami (Lapp) Tent ca. 1700-1900. In The Meanings of Things: Material Culture and Symbolic Expression. I. Hodder, ed. Pp. 249-262. London: Unwin Hyman. 